\title{
Prehypertension Among Middle-Aged and Elderly People in Taiwan: A Five-Year Follow-Up
}

\author{
Li-Kuo Liü, 2, 3 , Li-Ning Peng ${ }^{1,2,3}$, Liang-Kung Chen ${ }^{1,2,3}$, Shinn-Jang Hwang ${ }^{1,2,3}$, and Shu-Ti Chiou ${ }^{4}$ \\ ${ }^{1}$ Division of Geriatric Medicine, Department of Family Medicine, Taipei Veterans General Hospital, Taipei, Taiwan \\ ${ }^{2}$ Center for Geriatrics and Gerontology, Taipei Veterans General Hospital, Taipei, Taiwan \\ ${ }^{3}$ Department of Family Medicine, National Yang Ming University, School of Medicine, Taipei, Taiwan \\ ${ }^{4}$ Institute of Public Health and Department of Social Medicine, National Yang Ming University, School of Medicine, Taipei, Taiwan
}

\begin{abstract}
Aim: To evaluate the prevalence of prehypertension among middle-aged and elderly people in Taiwan and to explore the evolutionary changes of blood pressure in 5-year follow-up period.

Methods: In 2000, people aged over 40 participating in annual health examinations at local health stations in I-Lan County were invited to join the study. Past medical histories were reviewed, physical examinations and serial laboratory tests were performed for participants. All participants were followed in 2005 by a medical record review, telephone survey or personal visit. Subjects with prehypertension were sorted for further analysis.

Results: Overall, 1053 people (mean age $=64.4 \pm 11.4$ years, $44.4 \%$ males) were enrolled in the primary cohort. The prevalence of hypertension and prehypertension was $40.4 \%$ and $35.8 \%$, respectively. In 2005, 677 subjects (mean age: $68.8 \pm 10.4$ years, $42.5 \%$ males) were successfully followed, which revealed a significant increase of systolic blood pressure $(3.7 \pm 16.8 \mathrm{mmHg}, p<0.001)$, but not diastolic blood pressure $(0.3 \pm 11.5 \mathrm{mmHg}, p=0.758)$ in prehypertensive subjects; however, both systolic blood pressure $(14.3 \pm 17.4 \mathrm{mmHg}, p<0.001)$ and diastolic blood pressure $(7.7 \pm 13.3 \mathrm{mmHg}$, $p<0.001)$ were significantly increased among normotensive subjects. The cumulative incidence of prehypertensive subjects becoming hypertensive was $31.3 \%$, and those who became hypertensive were significantly older $(65.3 \pm 8.6$ vs. $62.2 \pm 12.3$ years, $p=0.024)$, having higher pulse pressure in $2000(49.6 \pm 10.6$ vs. $45.1 \pm 11.6 \mathrm{mmHg}, p=0.001)$, serum total cholesterol $(214.3 \pm 31.7$ vs. $204.0 \pm$ $37.2 \mathrm{mg} / \mathrm{dL}, p=0.020)$ and low-density lipoprotein-cholesterol $(141.7 \pm 29.2 \mathrm{vs.} 132.7 \pm 34.7 \mathrm{mg} / \mathrm{dL}$, $p=0.042$ ).

Conclusions: The prevalence of prehypertension among older Taiwanese was 35.8\% and the 5-year cumulative incidence of hypertension from prehypertension was $31.3 \%$. Older prehypertensive subjects with higher pulse pressure, higher serum total cholesterol and higher low-density lipoproteincholesterol were more likely to become hypertensive within 5 years.
\end{abstract}

J Atheroscler Thromb, 2010; 17:189-194.

Key words; Aged, Blood pressure, Cardiovascular disease, Hypertension, Prehypertension

\section{Introduction}

High blood pressure has long been recognized as a major risk factor of cardiovascular disease, and main-

Address for correspondence: Liang-Kung Chen, Division of Geriatric Medicine, Department of Family Medicine, Taipei Veterans General Hospital, Taipei 11217, Taiwan

E-mail: 1kchen2@vghtpe.gov.tw

Received: May 27, 2009

Accepted for publication: August 20, 2009 taining optimal blood pressure control is of great benefits to reduce cardiovascular disease ${ }^{1)}$. The Seventh Report of the Joint National Committee on Prevention, Detection, Evaluation, and Treatment of High Blood Pressure (JNC-7) has introduced a new classification of high blood pressure ${ }^{2)}$, replacing "high normal pressure" in JNC-6 with "prehypertension" ${ }^{3}$. After the introduction of prehypertension, a great number of studies started to explore the pathological implications, prognosis, and nature course of prehypertension 
in cardiovascular and cerebrovascular disease ${ }^{4-6)}$; however, aging alone is associated with a progressive uprising trend of systolic blood pressure ${ }^{7-9)}$, so older people are more likely to be prehypertensive or hypertensive. Although the official definition of hypertension remained unchanged, cardiovascular risk was significantly increased in the stage of prehypertension ${ }^{10}$.

The prevalence of prehypertension ranges between $31.2-33 \%$ in different countries ${ }^{11}, 12$. An Israeli study indicated that the prevalence of prehypertension was $23.2 \%$ in adults ${ }^{13)}$, and would increase up to $56.8 \%$ in men and $35.8 \%$ in women within 3 years ${ }^{14)}$. It has been reported that prehypertension is frequently associated with other CVD risk factors ${ }^{12)}$, a higher risk of developing myocardial infarction or coronary artery diseases ${ }^{15,16)}$, and higher probabilities of hospitalization and mortality ${ }^{17)}$. Although prehypertension has gained extensive research interest, awareness is low and treatment targeted to prehypertension remains unclear ${ }^{11,12)}$. Hence, the main purpose of this study was to evaluate the prevalence of prehypertension in Taiwan and to explore the progression of prehypertension to hypertension in a 5-year follow-up period.

\section{Methods}

\section{Participants}

In 2000, people aged over 40 in Sanhsing, Toucheng and Tongshan Townships of I-Lan County who participated in the health examinations held by community health stations were invited to join the study ${ }^{18-21)}$. Subjects were enrolled when they had fully consented. The whole study was approved by the ethical committee of National Yang Ming University.

\section{Demographic and Physical Examinations}

Experienced research staff recorded each subject's age, sex, and we measured each subject's height and weight. Body mass index (BMI) was calculated accordingly. Obesity was defined by the Recommendations of the International Obesity Task Force ${ }^{22)}$. Personal medical history was also recorded in detail. Blood pressure was measured according to the JNC-6 ${ }^{3)}$. A high blood pressure status was further classified into hypertension, prehypertension and normotension according to JNC-7 ${ }^{2}$.

\section{Laboratory Examinations}

All subjects underwent blood testing after a $10-\mathrm{h}$ overnight fast to measure serum levels of glucose, total cholesterol (TC), triglyceride (TG), high-density lipoprotein cholesterol (HDL-C) using an automatic ana- lyzer (Hitachi Model 736; Tokyo, Japan), and fasting insulin (FI) was measured by radioimmunoassay (Diagnostic Product Corporation, CA, USA).

\section{Diabetes and Insulin Resistance}

Diabetes mellitus (DM) was defined according to the criteria proposed by the American Diabetes Association in 2001 ${ }^{23)}$, and insulin resistance was measured by homeostasis model assessment (HOMA-IR) ${ }^{24)}$. The cutoff of HOMA-IR determining insulin resistance for all subjects was defined as the highest quartile of HOMA-IR among lean subjects (BMI $<25 \mathrm{~kg} /$ $\mathrm{m}^{2}$ ), and subjects with higher HOMA-IR were considered insulin resistant ${ }^{25)}$.

\section{Statistical Analysis}

Data in the text and tables are expressed as mean values \pm standard deviation (mean \pm SD). Groups with subjects with and without prehypertension were compared with the Chi square test, Fisher's Exact test, or Student's $t$-test when appropriate (SPSS 13.0, Chicago, IL, USA). One-way ANOVA was used to evaluate differences between variables for each different blood pressure status. For all tests, $p$ values 0.05 (twotailed) were considered significant.

\section{Results}

\section{Demography}

In total, 1053 people participated in this study (mean age $=64.4 \pm 11.4$ years and $44.4 \%$ males). The prevalence of normotension, prehypertension and hypertension was $23.8 \%, 35.8 \%$ and $40.4 \%$, respectively. Among all hypertensive subjects, 190 (44.7\%) subjects were aware of their hypertension status or currently on anti-hypertensive treatment. Comparisons of demographic data showed that age, prevalence of DM, insulin resistance, BMI, pulse pressure, TC, HDL-C, triglycerides, and HOMA-IR were significantly different between subjects with a different blood pressure status (Table 1).

\section{Five-Year Follow-Up of Subjects with Different Blood Pressure Status}

In 2005, 677 subjects (mean age: 68.8 \pm 10.4 years, $42.5 \%$ males) were successfully followed. Blood pressure and DM status were evaluated again in 2005. Comparisons of subjects with normotension and prehypertension showed a significant increase of systolic blood pressure but not diastolic blood pressure in the prehypertensive group and both systolic and diastolic blood pressure were significantly increased in the normotensive group (Table 2). Overall, the 5-year cumu- 
Table 1. Comparison of demographic data between subjects with different blood pressure status

\begin{tabular}{|c|c|c|c|c|}
\hline & Normotension $(n=251)$ & Prehypertension $(n=377)$ & Hypertension $(n=425)$ & $p$ value \\
\hline Age (year) & $61.0 \pm 12.3$ & $63.8 \pm 11.7$ & $67.0 \pm 9.8$ & $<0.001$ \\
\hline Males (\%) & 47.4 & 44.6 & 42.6 & $0.475^{*}$ \\
\hline Diabetes mellitus (\%) & 11.2 & 10.1 & 21.2 & $<0.001^{*}$ \\
\hline Insulin resistance (\%) & 28.4 & 34.3 & 43.3 & $0.001^{*}$ \\
\hline Body mass index $\left(\mathrm{kg} / \mathrm{m}^{2}\right)$ & $23.5 \pm 3.6$ & $24.2 \pm 3.4$ & $25.5 \pm 3.8$ & $<0.001$ \\
\hline Pulse pressure (mmHg) & $41.6 \pm 9.3$ & $48.1 \pm 11.4$ & $61.5 \pm 18.4$ & $<0.001$ \\
\hline Fasting glucose (mg/dL) & $104.1 \pm 34.1$ & $104.5 \pm 43.4$ & $110.0 \pm 36.6$ & 0.069 \\
\hline Total cholesterol (mg/dL) & $202.8 \pm 44.2$ & $206.9 \pm 35.4$ & $212.4 \pm 42.0$ & 0.009 \\
\hline HDL-cholesterol (mg/dL) & $47.5 \pm 16.9$ & $47.4 \pm 17.6$ & $44.4 \pm 17.7$ & 0.034 \\
\hline LDL-cholesterol (mg/dL) & $133.6 \pm 42.4$ & $135.2 \pm 32.9$ & $137.5 \pm 37.9$ & 0.445 \\
\hline Triglycerides (mg/dL) & $117.9 \pm 76.6$ & $126.5 \pm 76.4$ & $148.7 \pm 143.5$ & 0.001 \\
\hline HOMA-IR & $1.5 \pm 2.9$ & $1.5 \pm 2.1$ & $2.0 \pm 2.8$ & 0.018 \\
\hline
\end{tabular}

* by Chi square test

$\mathrm{HDL}=$ high-density lipoprotein, $\mathrm{LDL}=$ low-density lipoprotein, HOMA-IR = homeostasis model assessment

Table 2. Evolutionary changes of blood pressure among subjects with prehypertension and normotension

\begin{tabular}{lccc}
\hline & & Prehypertension & Normotension \\
\hline \multirow{2}{*}{ Year 2000} & SBP $(\mathrm{mmHg})$ & $127.5 \pm 8.1$ & $107.6 \pm 8.2$ \\
& DBP $(\mathrm{mmHg})$ & $78.7 \pm 7.8$ & $67.0 \pm 7.7$ \\
\hline \multirow{2}{*}{ Year 2005} & SBP $(\mathrm{mmHg})$ & $132.1 \pm 17.4$ & $122.7 \pm 17.9$ \\
& $\mathrm{DBP}(\mathrm{mmHg})$ & $78.9 \pm 11.1$ & $76.3 \pm 11.0$ \\
\hline \multicolumn{2}{l}{ Change of SBP $(\mathrm{mmHg})^{*}$} & $4(-41,66) \mathrm{mmHg}$ & $12(-29,73) \mathrm{mmHg}$ \\
\hline \multicolumn{2}{l}{ Change of DBP $(\mathrm{mmHg})^{*}$} & $0(-31,35) \mathrm{mmHg}$ & $7(-38,43) \mathrm{mmHg}$ \\
\hline
\end{tabular}

$\mathrm{SBP}=$ systolic blood pressure; $\mathrm{DBP}=$ diastolic blood pressure.

Changes in SBP (DBP) were identified by SBP (DBP) in 2005 minus SBP (DBP) in 2000 for each subject and expressed as the median (range).

${ }^{*} p<0.001$ by paired $t$-test within group

lative incidence of new onset DM in this study was $9.0 \%$, which was $8.8 \%, 6.9 \%, 10.9 \%$ in the normotension, prehypertension and hypertension groups, respectively. No statistical significance was found for the incidence of new onset DM between different blood pressure groups ( $p=0.289$ by Chi square test).

\section{Evolutionary Changes of Subjects with Prehyper- tension}

Among 377 subjects with prehypertension (mean age $=63.9 \pm 11.5$ years, $45.9 \%$ males $)$ in 2000,316 (mean age $=68.4 \pm 11.4$ years, $44.6 \%$ males) were successfully followed in 2005. Overall, after 5-year follow-up, 19 (6.0\%) had returned to normotension, $198(62.7 \%)$ were maintaining prehypertension, and 99 (31.3\%) had become hypertensive. The 5-year cumulative incidence of subjects with prehypertension progressing to hypertension was $31.3 \%$. Comparisons between these prehypertensive subjects who maintained prehypertension and progressed to hypertension showed that age, pulse pressure, TC and LDL-C were significantly different between groups (Table 3); however, using a multiple regression model, we found that none of the aforementioned factors could independently predict new-onset hypertension during the follow-up period.

\section{Evolutionary Changes of Subjects with Normoten- sion}

Among 251 (mean age $=60.6 \pm 12.6$ years, $45.4 \%$ males) normotensive subjects in 2000, 163 (mean age $=64.1 \pm 13.3$ years, $45.4 \%$ males) were successfully followed in 2005. Among them, 66 (40.5\%) remained normotensive, $50(30.7 \%)$ became prehypertensive, and $47(28.8 \%)$ became hypertensive. The 5-year cumulative incidence among normotensive subjects 
Table 3. Comparisons of prehypertensive subjects becoming hypertensive between 2000-2005

\begin{tabular}{|c|c|c|c|}
\hline & \multicolumn{2}{|c|}{$\begin{array}{l}\text { Blood pressure status in } 2005 \text { of initial } \\
\text { prehypertensive subjects }(n=316)\end{array}$} & \multirow{2}{*}{$p$ value } \\
\hline & Prehypertension $(n=198)$ & Hypertension $(n=99)$ & \\
\hline Age $^{*}$ & $62.2 \pm 12.3$ & $65.3 \pm 8.6$ & 0.024 \\
\hline Males $(\%)^{*}$ & 47.0 & 40.4 & 0.285 \\
\hline Diabetes mellitus (\%) & 6.0 & 8.2 & 0.374 \\
\hline Insulin resistance (\%) & 33.7 & 39.0 & 0.428 \\
\hline Body mass index $\left(\mathrm{kg} / \mathrm{m}^{2}\right)$ & $24.4 \pm 3.5$ & $24.4 \pm 3.5$ & 0.983 \\
\hline Pulse pressure $(\mathrm{mmHg})^{*}$ & $45.1 \pm 11.6$ & $49.6 \pm 10.6$ & 0.001 \\
\hline Fasting glucose $(\mathrm{mg} / \mathrm{dL})$ & $101.9 \pm 31.0$ & $111.4 \pm 67.8$ & 0.097 \\
\hline Total cholesterol $(\mathrm{mg} / \mathrm{dL})^{*}$ & $204.0 \pm 37.2$ & $214.3 \pm 31.7$ & 0.020 \\
\hline HDL cholesterol (mg/dL) & $47.6 \pm 17.8$ & $46.4 \pm 17.4$ & 0.609 \\
\hline LDL cholesterol $(\mathrm{mg} / \mathrm{dL})^{*}$ & $132.7 \pm 34.7$ & $141.7 \pm 29.2$ & 0.042 \\
\hline Triglycerides (mg/dL) & $122.6 \pm 76.6$ & $139.4 \pm 78.8$ & 0.077 \\
\hline HOMA-IR & $1.4 \pm 1.8$ & $1.7 \pm 2.6$ & 0.350 \\
\hline
\end{tabular}

${ }^{*} p<0.05$ by Fisher's Exact test or Student's $t$-test

$\mathrm{HDL}=$ high-density lipoprotein, $\mathrm{LDL}=$ low-density lipoprotein, HOMA-IR=homeostasis model assessment Insulin resistance was defined as HOMA-IR $>1.23$ in this study

Table 4. Comparisons of normotensive subjects becoming prehypertension and hypertension between 2000-2005

\begin{tabular}{|c|c|c|c|}
\hline & \multicolumn{2}{|c|}{$\begin{array}{l}\text { Blood pressure status in } 2005 \text { of initial } \\
\text { normotensive subjects }(n=163)\end{array}$} & \multirow{2}{*}{$p$ value } \\
\hline & Prehypertension $(n=50)$ & Hypertension $(n=47)$ & \\
\hline Age & $62.0 \pm 9.8$ & $63.4 \pm 9.3$ & 0.473 \\
\hline Males $(\%)^{*}$ & $46 \%$ & $38.3 \%$ & 0.538 \\
\hline Diabetes mellitus (\%) & $6 \%$ & $14.9 \%$ & 0.191 \\
\hline Insulin resistance $(\%)$ & $27.3 \%$ & $38.3 \%$ & 0.336 \\
\hline Body mass index $\left(\mathrm{kg} / \mathrm{m}^{2}\right)^{*}$ & $23.7 \pm 3.4$ & $25.2 \pm 3.4$ & 0.032 \\
\hline Pulse pressure $(\mathrm{mmHg})^{*}$ & $40.7 \pm 8.3$ & $44.6 \pm 8.9$ & 0.031 \\
\hline Fasting glucose (mg/dL) & $108.9 \pm 50.3$ & $106.3 \pm 30.2$ & 0.764 \\
\hline Total cholesterol (mg/dL) & $205.6 \pm 41.2$ & $208.7 \pm 45.5$ & 0.725 \\
\hline HDL cholesterol (mg/dL) & $44.9 \pm 15.4$ & $46.2 \pm 16.9$ & 0.720 \\
\hline LDL cholesterol (mg/dL) & $137.6 \pm 39.4$ & $139.1 \pm 39.3$ & 0.861 \\
\hline Triglycerides (mg/dL) & $122.6 \pm 76.6$ & $139.4 \pm 78.8$ & 0.077 \\
\hline HOMA-IR & $1.3 \pm 1.5$ & $2.2 \pm 5.1$ & 0.297 \\
\hline
\end{tabular}

${ }_{p} p 0.05$ by Fisher's Exact test or Student's $t$-test

$\mathrm{HDL}=$ high-density lipoprotein, $\mathrm{LDL}=$ low-density lipoprotein, $\mathrm{HOMA}-\mathrm{IR}=$ homeostasis model assessment Insulin resistance was defined as HOMA-IR $>1.23$ in this study

was $28.8 \%$. The conversion rate between prehypertensive subjects and normotensive subjects was not significantly different $(31.3 \%$ vs. $28.8 \%, p=0.572)$. Comparisons between normotensive subjects who became prehypertensive and hypertensive showed that only BMI and pulse pressure were significantly different between groups (Table 4).

\section{Discussion}

The prevalence of prehypertension was $35.8 \%$ in this study, higher than previously reported in an other Taiwanese city ${ }^{11}$. Results of the Nutrition and Health Survey in Taiwan (NAHSIT) disclosed that the overall prevalence of prehypertension was $34 \%$ in Taiwanese adults ${ }^{26)}$, similar to the results from the NHANES III 
in the United States $(33 \%)^{12)}$. In spite of differences in ethnicity and geographic factors, the prevalence of prehypertension is similar in different studies. Comparisons between subjects with different blood pressure status showed significant differences in age, DM, insulin resistance, BMI, pulse pressure, and the lipid profile. The results clearly showed a complex interrelationship between blood pressure and other cardiovascular risk factors, which has been reported previously ${ }^{11,12)}$.

During the 5-year follow-up period, the cumulative incidence of prehypertension to hypertension was $31.3 \%$; however, evolutional changes of blood pressure among subjects in normotension and prehypertension groups were significantly different. Both systolic and diastolic blood pressure increased in normotensive subjects, but only systolic blood pressure was significantly increased in prehypertensive subjects. This discrepancy may be explained by aging, in which systolic blood pressure kept increasing after middle age but diastolic blood pressure fell after the age of $60^{7-9)}$. The progression rate of normotension and prehypertension to hypertension was not significantly different in this study. This is an interesting finding because the role of prehypertension as the intermediate state of normotension and hypertension may be questioned. Due to the relatively older age and small study sample, further study is needed to clarify when prehypertension is of the same prognostic value in older people as in the adult and middle-aged population. In addition, it has been reported that DM and impaired glucose tolerance were significantly increased in prehypertensive subjects, and their influences extended into hypertensive subjects ${ }^{27,28)}$.

There are several limitations in this study. First, all blood pressure measurements were performed by research staff in the community health stations according to the principles of JNC-7; however, the "whitecoat" phenomenon may be unavoidable. A 24-hour ambulatory blood pressure measurement may overcome the "white-coat" phenomenon, but it is not practical in a community-based program. Second, not all potentially associative risk factors were collected in this study. For instance, the family history of diseases such as DM or hypertension was not fully obtained because the participants could not recall. Third, the study cohort was generated from a community health screening program in rural Taiwan, which can not be fully extrapolated to the general population; however, through comparisons of the prevalence of prehypertension, we believe that the study results are still applicable to other communities.

In conclusion, the prevalence of prehypertension among middle-aged and elderly people in rural Taiwan was $35.8 \%$ and $31.3 \%$ of prehypertensive subjects who would become hypertensive in the 5-year follow-up period. Prehypertension clustering with other cardiovascular risk factors was more likely to develop to hypertension. Further study is needed to evaluate the pathological implications of prehypertension and to design appropriate intervention programs to reverse the progression of prehypertension.

\section{References}

1) Lewington S, Clarke R, Qizilbash N, Peto R, Collins R; Prospective Studies Collaboration. Age-specific relevance of usual blood pressure to vascular mortality: a meta-analysis of individual data for one million adults in 61 prospective studies. Lancet, 2002; 360: 1903-1913

2) Chobanian AV, Bakris GL, Black HR, Cushman WC, Green LA, Izzo JL Jr, Jones DW, Materson BJ, Oparil S, Wright JT Jr, Roccella EJ; National Heart, Lung, and Blood Institute Joint National Committee on Prevention, Detection, Evaluation, and Treatment of High Blood Pressure; National High Blood Pressure Education Program Coordinating Committee. The Seventh Report of the Joint National Committee on Prevention, Detection, Evaluation, and Treatment of High Blood Pressure: the JNC 7 report. JAMA, 2003; 289: 2560-2572

3) Joint National Committee on Prevention Detection, Evaluation, and Treatment of High Blood Pressure. The sixth report of the Joint National Committee on prevention, detection, evaluation, and treatment of high blood pressure. Arch Intern Med, 1997; 157: 2413-2446

4) Vasan RS, Larson MG, Leip EP, Evans JC, O’Donnell CJ, Kannel WB, Levy D: Impact of high-normal blood pressure on the risk of cardiovascular disease. N Engl J Med, 2001; 345: 1291-1297

5) Mainous AG 3rd, Everett CJ, Liszka H, King DE, Egan BM: Prehypertension and mortality in a nationally representative cohort. Am J Cardiol, 2004; 94: 1496-1500

6) MacMahon S, Peto R, Cutler J, Collins R, Sorlie P, Neaton J, Abbott R, Goodwin J, Dyer A, Stamler J: Blood pressure, stroke, and coronary heart disease. Part 1, prolonged differences in blood pressure: prospective observational studies corrected for the regression dilution bias. Lancet, 1990; 335: 765-774

7) Miall WE: Hypertension in the elderly: the South Wales Study. In: Onesti G, Kim KE, eds. Hypertension in the Young and Old. 1st ed. New York, NY: Grune \& Stratton; 1981: 277-283

8) Whelton PK: Blood pressure in adults and the elderly. In: Bulpitt CJ, ed. Handbook of Hypertension. Vol 6. Amsterdam, Netherlands: Elsevier; 1985: 51-69

9) Franklin SS, Gustin W 4th, Wong ND, Larson MG, Weber MA, Kannel WB, Levy D: Hemodynamic patterns of age-related changes in blood pressure. The Framingham Heart Study. Circulation, 1997; 96: 308-315

10) Wolf-Maier K, Cooper RS, Banegas JR, Giampaoli S, Hense HW, Joffres M, Kastarinen M, Poulter N, Prima- 
testa P, Rodriguez-Artalejo F, Stegmayr B, Thamm M, Tuomilehto J, Vanuzzo D, Vescio F: Hypertension prevalence and blood pressure levels in 6 European countries, Canada, and the United States. JAMA, 2003; 289: $2363-$ 2369

11) Chiu YH, Wu SC, Tseng CD, Yen MF, Chen TH: Progression of pre-hypertension, stage 1 and 2 hypertension (JNC 7): a population-based study in Keelung, Taiwan (keelung Community-based integrated No.9). J Hypertens, 2006; 24: 821-828

12) Greenlund KJ, Croft JB, Mensah GA: Prevalence of heart disease and stroke risk factors in persons with prehypertension in the United States, 1999-2000. Arch Intern Med, 2004;164: 2113-2118

13) Kitai E, Vinker S, Halperin L, Meidan A, Grossman E: Pre-hypertension is a common phenomenon: national database study. Isr Med Assoc J, 2007; 9: 8-11

14) Israeli E, Schochat T, Korzets Z, Tekes-Manova D, Bernheim J, Golan E: Prehypertension and obesity in adolescents: a population study. Am J Hypertens, 2006; 19: 708-712

15) Qureshi AI, Suri MF, Kirmani JF, Divani AA, Mohammad Y: Is prehypertension a risk factor for cardiovascular diseases? Stroke, 2005; 36: 1859-1863

16) Liszka HA, Mainous AG 3rd, King DE, Everett CJ, Egan BM: Prehypertension and cardiovascular morbidity. Ann Fam Med, 2005; 3: 294-299

17) Russell LB, Valiyeva E, Carson JL: Effects of prehypertension on admissions and deaths: a simulation. Arch Intern Med, 2004; 164: 2119-2124

18) Chen LK, Lin MH, Chen ZJ, Hwang SJ, Chiou ST: Association of insulin resistance and hematologic parameters: study of a middle-aged and elderly Chinese population in Taiwan. J Chin Med Assoc, 2006; 69: 248-253

19) Chen LK, Lin MH, Chen ZJ, Hwang SJ, Tsai ST, Chiou ST: Metabolic characteristics among subjects with impaired fasting glucose in I-Lan. Diabetes Res Clin Pract, 2006; 71: 170-176

20) Chen LK, Lin MH, Lai HY, Hwang SJ, Chiou ST: Uric acid: a surrogate of insulin resistance in older women. Maturitas 2008; 59: 55-61

21) Chen LK, Peng LN, Lin MH, Lai HY, Hwang SJ, Chiou ST: Predicting new onset diabetes mellitus in older Taiwanese: metabolic syndrome or impaired fasting glucose. J Artheroscler Thromb, 2009; 16: 627-632

22) World Health Organization: The Asia-Pacific perspective: Redefining obesity and its treatment. WHO Geneva, 2000

23) The Expert Committee of the Diagnosis, Classification of Diabetes Mellitus, Report of the expert committee on the diagnosis and classification of diabetes mellitus. Diabetes Care, 1997; 20: 1183-1197

24) Matthews DR, Hosker JP, Rudenski AS, Naylor BA, Treacher DF, Turner RC: Homeostasis model assessment: insulin resistance and beta-cell function from fasting plasma glucose and insulin concentrations in man. Diabetologia, 1985; 28: 412-419

25) Ferrannini E, Balkau B: Insulin: In search of a syndrome. Diabet Med, 2002; 19: 724-729

26) Tsai PS, Ke TL, Huang CJ, Tsai JC, Chen PL, Wang SY, Shyu YK: Prevalence and determinants of prehypertension status in the Taiwanese general population. J Hypertens, 2005; 23: 1355-1360

27) Yadav S, Boddula R, Genitta G, Bhatia V, Bansal B, Kongara S, Julka S, Kumar A, Singh HK, Ramesh V, Bhatia E: Prevalence \& risk factors of prehypertension \& hypertension in an affluent north Indian population. Indian J Med Res, 2008; 128: 712-720

28) Okosun IS, Boltri JM, Anochie LK, Chandra KM: Racial/ ethnic differences in prehypertension in American adults: population and relative attributable risks of abdominal obesity. J Hum Hypertens, 2004; 18: 849-855 